Journal of Advanced Research in Fluid Mechanics and Thermal Sciences

Journal homepage: www.akademiabaru.com/arfmts.html ISSN: 2289-7879

\title{
Finite Difference Solution for MHD Flow Between Two Parallel Permeable Plates with Velocity Slip
}

\author{
Nagaraj N. Katagi ${ }^{1}$, Ashwini Bhat ${ }^{1, *}$ \\ 1 Department of Mathematics, Manipal Institute of Technology, MAHE, Manipal, India
}

\begin{tabular}{ll} 
ARTICLE INFO & ABSTRACT \\
\hline $\begin{array}{l}\text { Article history: } \\
\text { Received 12 June 2020 }\end{array}$ & $\begin{array}{l}\text { The problem of Hydromagnetic steady laminar flow of an electrically conducting } \\
\text { Received in revised form 15 July } 2020\end{array}$ \\
$\begin{array}{l}\text { Accepted 21 July 2020 } \\
\text { tangential slip velocity at the permeable boundary is considered. A numerical solution } \\
\text { Available online 25 October 2020 }\end{array}$ & $\begin{array}{l}\text { is derived for the governing nonlinear boundary value problem using a novel Keller box } \\
\text { scheme. The effect of suction Reynold number } R \text {, Hartman number } M \text { and slip } \\
\text { coefficient } \phi \text { on derived quantities such as velocity filed and skin friction at the } \\
\text { boundaries are analyzed. The physical significance of the flow parameters is also } \\
\text { discussed. }\end{array}$
\end{tabular}

Keywords:

MHD flow; Slip velocity; Keller-box method; Hartmann number; Reynolds number

Copyright @ 2020 PENERBIT AKADEMIA BARU - All rights reserved

\section{Introduction}

The study of Magentohydrodynamics (MHD) flow of an incompressible, viscous and electrically conducting fluid between two porous plates not only possesses the theoretical appeal but also has many real-world engineering applications such as magentohydrodynamic pumps, geothermal energy extraction, MHD generators [1]. A useful survey of MHD theory and its applications can be found in the book by Moreau [2]. Owing to its important applications, researchers have used this phenomenon to study fluid flow behavior under various geometries, like vertical plates, stretching sheets, channels, tubes, and disks. Hartmann [3] investigated the impact of a transverse uniform magnetic field on the steady flow of an electrically conducting fluid between two parallel plates.

The problem of homogeneous fluid flowing between porous walls with uniform suction at the wall was first investigated by Berman [4] and obtained the perturbation solution for the velocity field for small suction Reynold number. Later, Berman's problem was extended by many researchers for both small and large Reynold number [5-12]. A distinctive evaluation of forced convection heat transfer to an electrically conducting liquid flowing in a channel with a transverse magnetic field was

\footnotetext{
* Corresponding author.

E-mail address: ashwini.bhat@manipal.edu
}

https://doi.org/10.37934/arfmts.76.3.3848 
carried by Perlmutter and Siegel [13]. Subsequently, Attia and Kotb [14] and Attia [15] investigated the effect of temperature based viscosity on the magentohydrodynamic flow in a channel. The steady MHD flow and heat transfer induced by an exponentially shrinking sheet with partial slip, thermal radiation and suction was investigated using MATLAB bvp4c solver by Adnan et al., [16]. MHD slip Darcy flow of viscoelastic fluid over a stretching surface in a porous medium with thermal radiation and viscous dissipation was analytically examined by Wahid et al., [17].

Most of the above analysis are confined to no-slip boundary conditions. But the velocity slip being present at the permeable boundaries has a remarkable effect on the fluid flow [18-21]. In the present study, the problem of magnetohydrodynamic flow of an incompressible viscous fluid flowing between two parallel porous plates is investigated in the presence of external magnetic field and velocity slip boundary conditions at the permeable boundaries. The numerical solution of the governing problem is obtained and is analyzed for all flow parameters using the Keller-box method. Keller [22] used this scheme for solving diffusion problems, but it has subsequently been applied to a broad class of problems. A sketch of applications of this box scheme to a variety of boundary layer flow problems is given in researches by Keller [23] and Vajravelu and Prasad [24].

An outline of the rest of this paper is as follows. In section (2) mathematical formulation of the proposed problem is explained. Section (3) devotes to obtain a numerical solution of the governing problem and section (4) presents results and discussions. Important conclusions from the study are given in section (5).

\section{Mathematical Formulation}

The steady laminar flow of an incompressible viscous fluid between two parallel porous plates is considered with slip at the porous boundaries. An external magnetic field of strength $H_{0}$ is applied in the direction perpendicular to the walls. Assuming a $X Y$ - coordinate system with the origin at center of the channel, $L$ be the length of the channel with $2 l$ being the distance between two plates as shown in Figure 1 . Let $u$ and $v$ be the velocity components in the $x$ and $y$ directions, respectively.

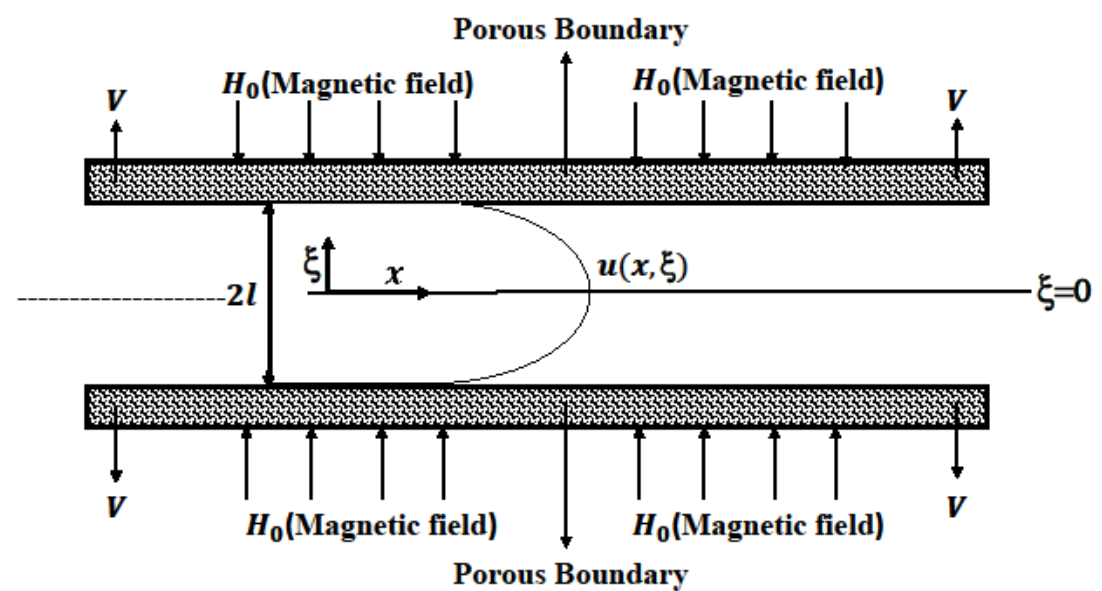

Fig. 1. Geometry of viscous fluid flow between porous plates

The governing equations of motion along with continuity equation are

$\frac{\partial u}{\partial x}+\frac{1}{l} \frac{\partial v}{\partial \xi}=0$ 
$u \frac{\partial u}{\partial x}+\frac{v}{l} \frac{\partial u}{\partial \xi}=-\frac{1}{\rho} \frac{\partial p}{\partial x}+v\left(\frac{\partial^{2} u}{\partial x^{2}}+\frac{1}{l^{2}} \frac{\partial^{2} u}{\partial \xi^{2}}\right)-\frac{\sigma B^{2} u}{\rho}$

$u \frac{\partial v}{\partial x}+\frac{v}{l} \frac{\partial v}{\partial \xi}=-\frac{1}{\rho l} \frac{\partial p}{\partial \xi}+v\left(\frac{\partial^{2} v}{\partial x^{2}}+\frac{1}{l^{2}} \frac{\partial^{2} v}{\partial \xi^{2}}\right)$

where, $\sigma$ is the electrical conductivity and $B=\mu_{e} H_{0}, \mu_{e}$ is the magnetic permeability. Also, $\xi=\frac{y}{l}$ is the dimensionless variable, $\rho$ is the density, $p$ is the pressure. The appropriate boundary conditions are;

$u(x, \pm 1)= \pm u_{\text {slip }}$

$v(x, \pm 1)= \pm V$

where $u_{\text {slip }}=-\frac{\sqrt{k}}{\alpha l} \frac{\partial u}{\partial \eta}$ is the slip velocity and $V$ is the suction velocity at walls of the channel. By introducing the stream function of the form [4]

$\psi(x, y)=(l U(0)-V x) F(\xi)$

where $U(0)$ is the average entrance velocity at $x=0$. The expressions for axial and radial components of velocity can be derived as

$u=\frac{1}{l}(l U(0)-V x) F^{\prime}(\xi)$

$v=V F(\xi)$

Substituting Eq. (7) and Eq. (8) in Eq. (2) and Eq. (3) the momentum equations reduces to $-\frac{1}{\rho} \frac{\partial p}{\partial x}=\left(U(0)-\frac{V x}{l}\right)\left(\frac{V}{l}\left(F F^{\prime \prime}-F^{2}\right)-\frac{v}{l^{2}} F^{\prime \prime \prime}+\frac{\sigma B^{2}}{\rho} F^{\prime}\right)-\frac{1}{l p} \frac{\partial p}{\partial \xi}=\frac{V^{2}}{l} F F^{\prime}-\frac{v V}{l^{2}} F^{\prime \prime}$

Eliminating the pressure term and upon simplification, we have,

$\frac{d}{d \xi}\left(\frac{V}{l}\left(F F^{\prime \prime}-F^{2}\right)-\frac{v}{l^{2}} F^{\prime \prime \prime}+\frac{\sigma B^{2}}{\rho} F^{\prime}\right)=0$

$F^{\prime \prime \prime}+R\left(F^{\prime 2}-F F^{\prime \prime}\right)-a R F^{\prime}=K$

where $R=\frac{l V}{v}$ is suction Reynolds number, $a=\frac{H_{0}^{2} \mu_{e}^{2} \sigma l}{\rho V}$ and $K$ is an arbitrary constant. Consider $a R=$ $M^{2}$, with $M=B l\left(\frac{\sigma}{v p}\right)^{1 / 2}$ called Hartmann number. The boundary conditions can be rewritten as

$F(1)=1, F^{\prime}(1)=-\phi F^{\prime \prime}(1), F(-1)=-1, F^{\prime}(-1)=\phi F^{\prime \prime}(-1)$

where $\phi=\frac{\sqrt{k}}{\alpha l}$ is the slip coefficient. 


\section{Finite Difference Solution}

The fourth-order differential equation in Eq. (10) governing the flow along with the suitable boundary conditions in Eq. (11) is solved by a novel finite-difference technique developed by Keller also known as the 'box' method. This Keller box method is an implicit scheme with second-order accuracy in both space and time. This scheme differs from other techniques, where the second and higher-order derivatives are replaced by first derivatives through the introduction of additional variables, which results in a system of first-order equations. And then, these first-order derivatives are approximated using appropriate differences, which gives a system of difference equations. Using suitably the boundary conditions result in an algebraic block tri-diagonal system and can be solved with the general block tri-diagonal algorithm.

The method begins with introducing new variables to reduce the fourth order governing equation to four system of first order equations as follows.

$$
\begin{aligned}
& U=F^{\prime}, V=F^{\prime \prime}, W=F^{\prime \prime \prime} \\
& W^{\prime}+R(U V-F W)-M^{2} V=0
\end{aligned}
$$

The corresponding boundary conditions can be written as

$$
\begin{array}{ll}
F(1)=1, & F(-1)=-1 \\
U(1)=-\phi V(1), & U(-1)=\phi V(-1)
\end{array}
$$

Following this step, the system of first order equations are discretized by substituting the appropriate finite difference approximations. Accordingly, the system from Eq. (12) can be written as

$$
\begin{aligned}
& F_{j}-F_{j-1}=d_{j}\left(U_{j}+U_{j-1}\right) \\
& U_{j}-U_{j-1}=d_{j}\left(V_{j}+V_{j-1}\right) \\
& V_{j}-V_{j-1}=d_{j}\left(W_{j}+W_{j-1}\right) \\
& W_{j}-W_{j-1}+\frac{R d_{j}}{2}\left(U_{j}+U_{j-1}\right)\left(V_{j}+V_{j-1}\right)-\frac{R d_{j}}{2}\left(F_{j}+F_{j-1}\right)\left(W_{j}+W_{j-1}\right)-d_{j} M^{2}\left(V_{j}+V_{j-1}\right)=0
\end{aligned}
$$

This nonlinear discretized system is linearized using Newton's linearisation method. Substituting Newton's iterations as, ()$_{j}^{(i+1)}=\mathrm{O}_{j}^{(i)}+\delta \mathrm{O}_{j}^{(i)}$ for all the variables in the system, we obtain the following linear set of algebraic equations.

$$
\begin{aligned}
& \delta F_{j}-\delta F_{j-1}-d_{j}\left(\delta U_{j}+\delta U_{j-1}\right)=\left(r_{1}\right)_{j} \\
& \delta U_{j}-\delta U_{j-1}-d_{j}\left(\delta V_{j}+\delta V_{j-1}\right)=\left(r_{2}\right)_{j} \\
& \delta V_{j}-\delta V_{j-1}-d_{j}\left(\delta W_{j}+\delta W_{j-1}\right)=\left(r_{3}\right)_{j} \\
& \left(a_{1}\right)_{j} \delta W_{j}+\left(a_{2}\right)_{j} \delta W_{j-1}+\left(a_{3}\right)_{j}\left(\delta V_{j}+\delta V_{j-1}\right)+\left(a_{4}\right)_{j}\left(\delta U_{j}+\delta U_{j-1}\right)=\left(r_{4}\right)_{j}
\end{aligned}
$$


where,

$$
\begin{aligned}
& \left(a_{1}\right)_{j}=1-\frac{d_{j} R}{2}\left(F_{j}+F_{j-1}\right) \\
& \left(a_{2}\right)_{j}=-2+\left(a_{1}\right)_{j} \\
& \left(a_{3}\right)_{j}=\frac{R d_{j}}{2}\left(U_{j}+U_{j-1}\right)-M^{2} d_{j} \\
& \left(a_{4}\right)_{j}=\frac{-d_{j} R}{2}\left(W_{j}+W_{j-1}\right) \\
& \left(a_{5}\right)_{j}=-\frac{d_{j} R}{2}\left(V_{j}+V_{j-1}\right) \\
& \left(r_{1}\right)_{j}=d_{j}\left(U_{j}+U_{j-1}\right)+F_{j-1}-F_{j} \\
& \left(r_{2}\right)_{j}=d_{j}\left(V_{j}+V_{j-1}\right)+U_{j-1}-U_{j} \\
& \left(r_{3}\right)_{j}=d_{j}\left(W_{j}+W_{j-1}\right)+V_{j-1}-V_{j} \\
& \left(r_{4}\right)_{j}=M^{2} d_{j}\left(V_{j}+V_{j-1}\right)-\frac{R d_{j}}{2}\left(\left(U_{j-1}+U_{j}\right)\left(V_{j-1}+V_{j}\right)-\right. \\
& \left.\left(F_{j-1}+F_{j}\right)\left(W_{j-1}+W_{j}\right)\right)+W_{j-1}-W_{j}
\end{aligned}
$$

The linearized system of Eq. (18)-(21) have a block tri-diagonal structure which can be solved with the help of block elimination method. In vector -matrix form, Eq. (18)-(21) can be written as

$$
A \delta=r
$$

where,

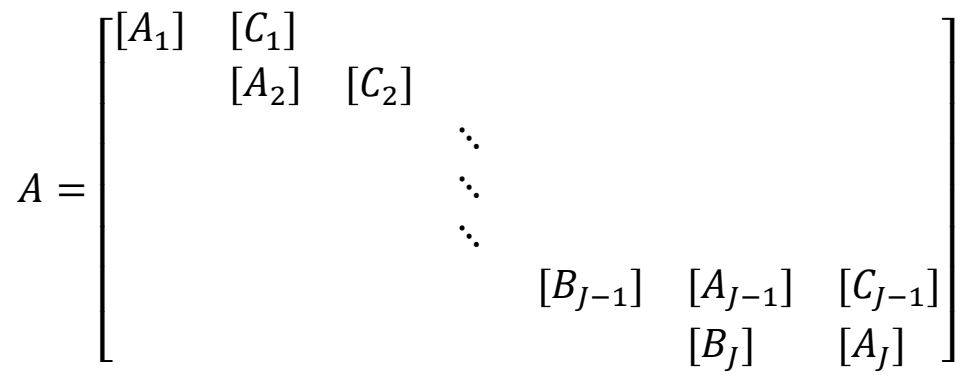

$\delta=\left[\begin{array}{l}{\left[\delta_{1}\right]} \\ \vdots\end{array}\right] \quad r=\left[\begin{array}{l}{\left[r_{1}\right]} \\ \vdots\end{array}\right]$

where in Eq. (32) the elements are defined by 
$\left[A_{j}\right]=\left[\begin{array}{llll}0 & 0 & 1 & -d_{j} \\ -d_{j} & 0 & 0 & 1 \\ -1 & -d_{j} & 0 & 0 \\ \left(a_{3}\right)_{j} & \left(a_{2}\right)_{j} & \left(a_{4}\right)_{j} & \left(a_{5}\right)_{j}\end{array}\right]$ for $1 \leq j \leq J-1 ; \quad\left[A_{J}\right]=\left[\begin{array}{llll}0 & 0 & 0 & 0 \\ -d_{j} & 0 & -d_{j} & 0 \\ -1 & -d_{j} & 1 & -d_{j} \\ \left(a_{3}\right)_{J} & \left(a_{2}\right)_{J} & \left(a_{3}\right)_{J} & \left(a_{1}\right)_{J}\end{array}\right]$

$\left[A_{J}\right]=\left[\begin{array}{llll}0 & 0 & 0 & 0 \\ -d_{j} & 0 & -d_{j} & 0 \\ -1 & -d_{j} & 1 & -d_{j} \\ \left(a_{3}\right)_{J} & \left(a_{2}\right)_{J} & \left(a_{3}\right)_{J} & \left(a_{1}\right)_{J}\end{array}\right] ; \quad\left[B_{j}\right]=\left[\begin{array}{llll}0 & 0 & -1 & -d_{j} \\ 0 & 0 & 0 & -1 \\ 0 & 0 & 0 & 0 \\ 0 & 0 & \left(a_{4}\right)_{j} & \left(a_{5}\right)_{j}\end{array}\right], \quad 2 \leq j \leq J$

$\left[C_{j}\right]=\left[\begin{array}{llll}0 & 0 & 0 & 0 \\ -d_{j} & 0 & 0 & 0 \\ 1 & -d_{j} & 0 & 0 \\ \left(a_{3}\right)_{j} & \left(a_{1}\right)_{j} & 0 & 0\end{array}\right], \quad 1 \leq j \leq J-1$

$\left[\delta_{j}\right]=\left[\begin{array}{llll}\delta V_{j-1} & \delta W_{j-1} & \delta F_{j} & \delta U_{j}\end{array}\right]^{T}, \quad 1 \leq j \leq J-1$

and

$\left[\delta_{J}\right]=\left[\begin{array}{llll}\delta V_{J-1} & \delta W_{J-1} & \delta V_{J} & \delta W_{J}\end{array}\right]^{T}$

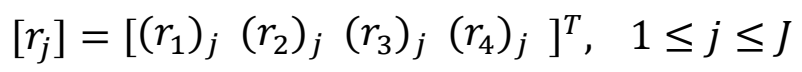

Now we write,

$A=L u$

where,

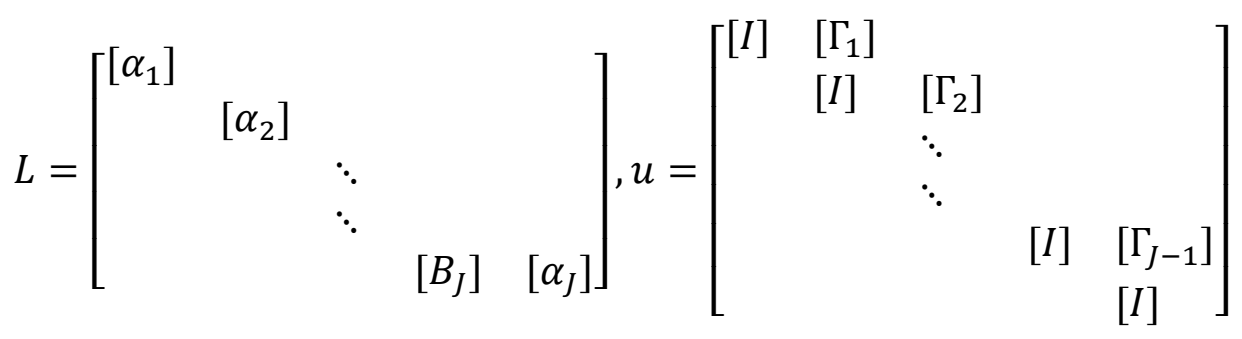

Here, $[I]$ is unit matrix and $\left[\alpha_{i}\right]$ and $\left[\Gamma_{i}\right]$ are $4 \times 4$ matrices whose elements are determined by the following equations

$\left[\alpha_{j}\right]=\left[A_{1}\right]$

$\left[A_{1}\right]\left[\Gamma_{1}\right]=\left[C_{1}\right]$

$\left[\alpha_{j}\right]=\left[A_{j}\right]-\left[B_{j}\right]\left[\Gamma_{j-1}\right], j=2,3,, J$

$\left[\alpha_{j}\right]\left[\Gamma_{j}\right]=\left[C_{j}\right], j=2,3,, J-1$ 
Eq. (34) substituted in Eq. (31) and we have

$L u \delta=r$

Defining $u \delta=w$, we have

$L w=r$

where,

$w=\left[\left[w_{1}\right]\left[w_{2}\right]\left[w_{3}\right]\left[w_{4}\right]\right]^{T}$

and the $\left[w_{j}\right]$ are $4 \times 1$ column matrices. The elements $w$ can be solved from Eq. (36)

$\left[\alpha_{1}\right]\left[w_{1}\right]=\left[r_{1}\right]$

$\left[\alpha_{j}\right]\left[w_{j}\right]=\left[r_{j}\right]-\left[B_{j}\right]\left[w_{j-1}\right]$

Once the elements of $w$ are found, solution for $\delta$ can be obtained using relations:

$\left[\delta_{J}\right]=\left[w_{J}\right]$

$\left[\delta_{j}\right]=\left[w_{j}\right]-\left[\Gamma_{j}\right]\left[\delta_{j+1}\right]$

Theses solution for $\delta$ can be used to find $(i+1)^{\text {th }}$ iteration.

\section{Results and Discussion}

The numerical study on Magnetohydrodynamics (MHD) flow between parallel plates with velocity slip at the permeable boundaries is performed using a novel Keller-Box method. We obtain the solution for the derived quantities from the governing non-linear boundary value problem and are shown in the graphs. The velocity profiles, both axial as well as radial velocity are plotted in Figure 2 to Figure 5 for different positive values of flow Reynold number $R$, Hartmann Number $M$ and slip coefficient $\phi$. The presence of both the slip coefficient and magnetic parameter decreased the magnitude of both axial and radial velocity profiles in general. The plot also reveals that as magnetic field intensity $M$ increases the axial velocity decreases near the central plane and fluid is pushed towards the boundaries. Moreover, as $M$ increases velocity profiles show the characteristic flattering. 

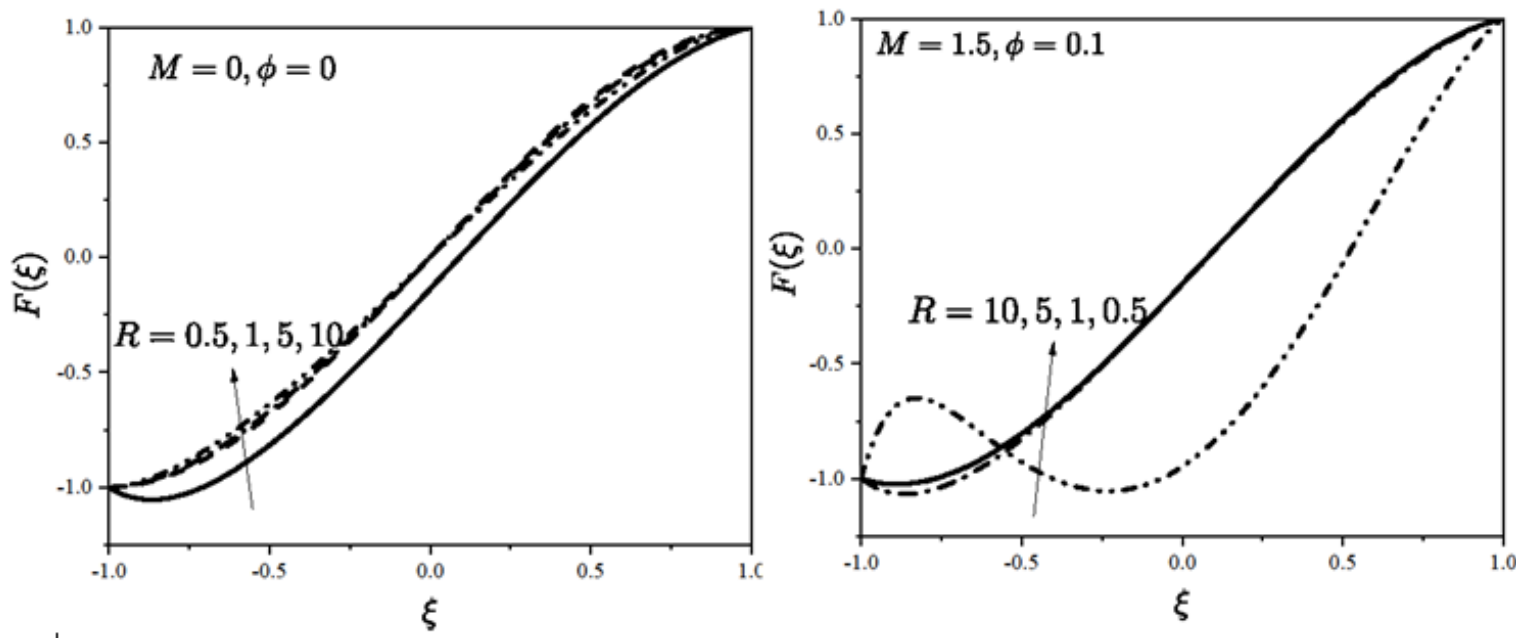

Fig. 2. Dimensionless Axial velocity for various Reynolds number with $M=0,1.5$ and $\phi=0,0.1$
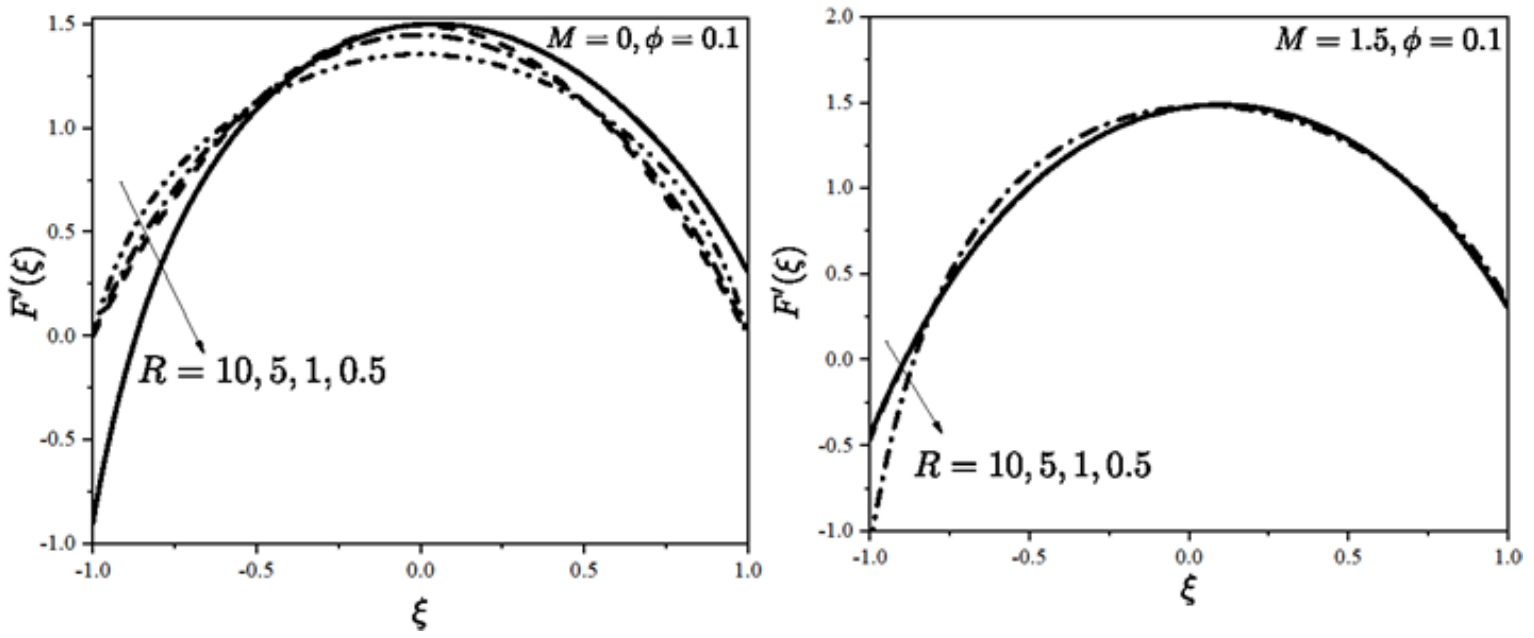

Fig. 3. Dimensionless radial velocity for various Reynolds number with $M=0,1.5$ and $\phi=0.1$
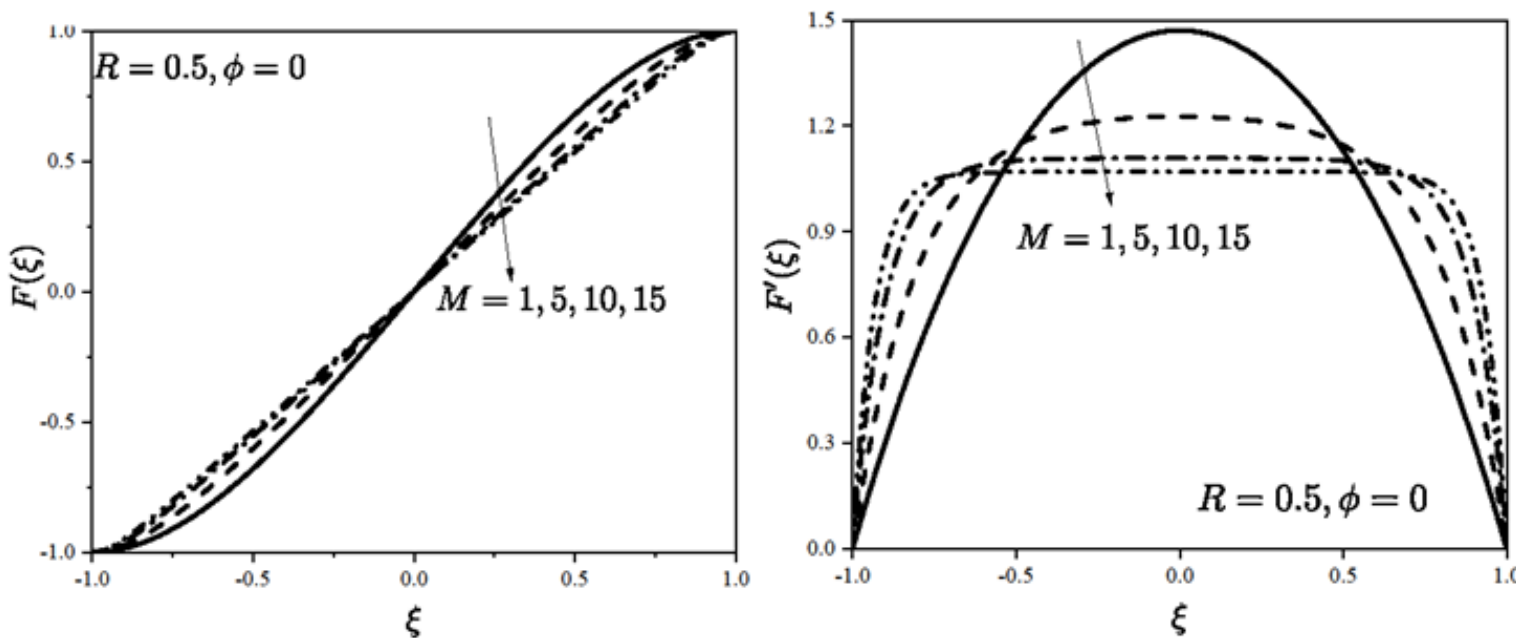

Fig. 4. Dimensionless Axial velocity and radial velocity for various $M$ with $R=0.5$ and $\phi=0$

When $\phi=0$ (no slip case) and $M=0$, the governing problem reduced to Berman's problem [4]. Moreover, it is evident from Figure 5 that increasing slip leads to flattening of profiles and reduced wall shear stress. A similar observation is made in Figure 2 for the positive value of flow Reynolds number $R$. Dimensionless radial velocity profiles depicted in Figure 3, which show the effect of slip 
coefficient $\phi$ for fixed suction and $M$. Irrespective of the values of pertinent parameters, the axial velocity profile takes its dimensionless value 1 at the upper plate and reduces to -1 at the plate and with a point of inflection near the central plane. From Figure 2, the negative axial velocity near the walls in the presence of slip proves the occurrence of flow reversal near the boundaries.
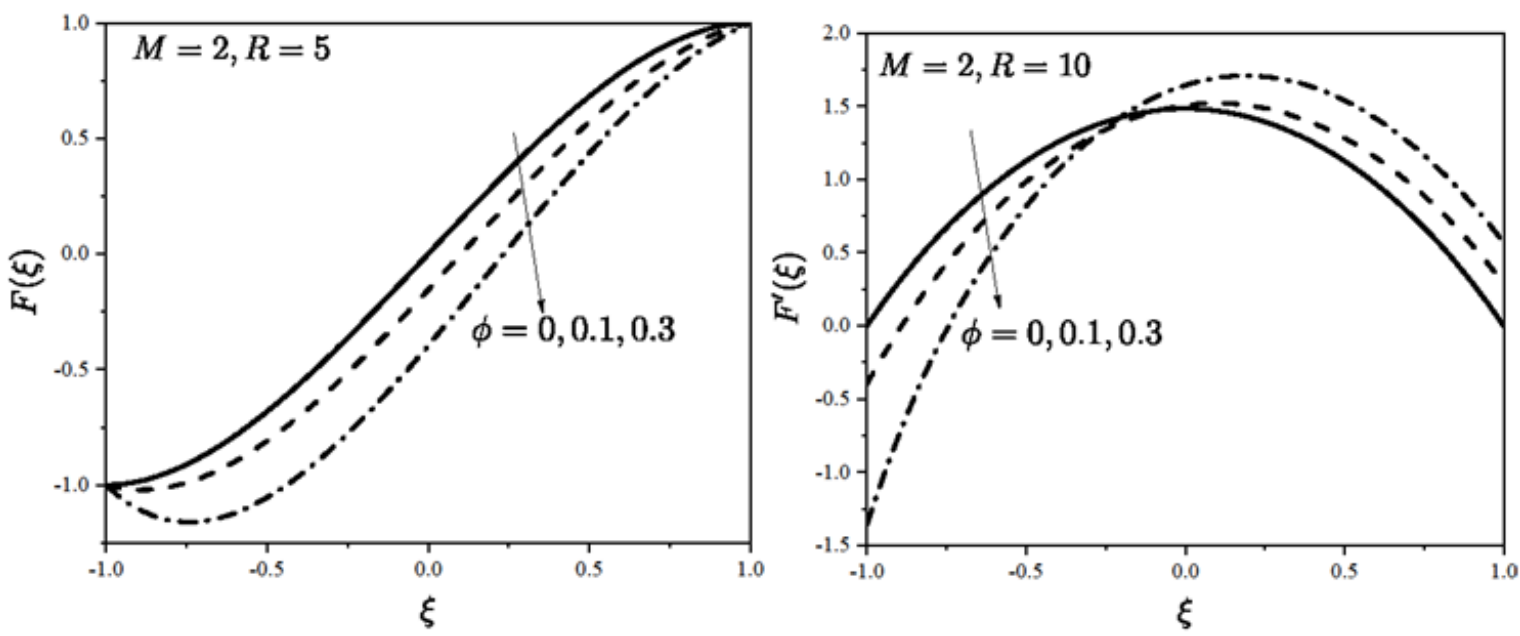

Fig. 5. Dimensionless Axial velocity and radial velocity for various slip coefficient $\phi$ with $M=2$

The coefficient of skin friction near the plate $-F^{\prime \prime}(1)$ is computed in the Table 1 . An increase in the magnitude of skin friction is seen with increasing suction. Meanwhile, a general decrease in the skin friction coefficient is observed with an increase in velocity slip.

Table 1

Calculation of skin friction coefficient $\left(-F^{\prime \prime}(1)\right)$ for different values of magnetic parameter $M$, Reynolds number $R$ and velocity slip parameter $\phi$

\begin{tabular}{lllll}
\hline$M$ & & $\phi=0$ & $\phi=0.1$ & $\phi=0.2$ \\
\hline 0 & $R=1$ & 3.0586 & 2.7935 & 2.7411 \\
0.5 & & 3.1122 & 2.8233 & 2.7709 \\
1 & & 3.2677 & 2.9091 & 2.8624 \\
1.5 & & 3.5099 & 3.0417 & 3.0274 \\
0 & $R=5$ & 3.6936 & 2.7098 & 1.8262 \\
0.5 & & 3.7901 & 2.7941 & 1.7891 \\
1 & & 4.0586 & 2.9996 & 1.9125 \\
1.5 & & 4.4494 & 3.2631 & 2.1764 \\
\hline
\end{tabular}

\section{Conclusion}

The present analysis focused on the finite difference solution to understand the combined effects of slip coefficient and magnetic field on the steady flow of viscous incompressible fluid flowing between two parallel plates with permeable boundaries. We infer that the fluid velocity is reduced by both the magnetic field and slip parameter. It is well known that the suction Reynolds number increases skin friction, the present study also reveals the effects of the magnetic field and slip velocity on the variation in skin friction at the porous boundaries. 


\section{References}

[1] Hayat, T., C. Fetecau, and M. Sajid. "Analytic solution for MHD transient rotating flow of a second grade fluid in a porous space." Nonlinear Analysis: Real World Applications 9, no. 4 (2008): 1619-1627.

https://doi.org/10.1016/j.nonrwa.2007.04.006

[2] Moreau, R. J. Magnetohydrodynamics. Springer Netherlands, 1990.

https://doi.org/10.1007/978-94-015-7883-7

[3] Hartmann, Jul. "Mercury dynamics I - Theory of the laminar flow of an electrically conductive liquid in a homogeneous magnetic field." Det Kgl. Danske Videnskabernes. Selskab. Mathematisk-fysiske Meddelelser 15, no. 6 (1937): 1-28.

[4] Berman, Abraham S. "Laminar flow in channels with porous walls." Journal of Applied Physics 24, no. 9 (1953): 12321235.

https://doi.org/10.1063/1.1721476

[5] Yuan, S. W. "Further investigation of laminar flow in channels with porous walls." Journal of Applied Physics 27, no. 3 (1956): 267-269.

https://doi.org/10.1063/1.1722355

[6] Terrill, R. M. "Laminar flow in a uniformly porous channel with large injection." The Aeronautical Quarterly 16, no. 4 (1965): 323-332.

https://doi.org/10.1017/S0001925900003565

[7] Terrill, R. M. "The flow between two parallel circular disks, one of which is subject to a normal sinusoidal oscillation." ASME Journal of Lubricant Technology 91, no. 1 (1969): 126-131.

https://doi.org/10.1115/1.3554844

[8] Robinson, W. A. "The existence of multiple solutions for the laminar flow in a uniformly porous channel with suction at both walls." Journal of Engineering Mathematics 10, no. 1 (1976): 23-40. https://doi.org/10.1007/BF01535424

[9] Brady, J. F. "Flow development in a porous channel and tube." The Physics of Fluids 27, no. 5 (1984): 1061-1067. https://doi.org/10.1063/1.864735

[10] Cox, Stephen M. "Analysis of steady flow in a channel with one porous wall, or with accelerating walls." SIAM Journal on Applied Mathematics 51, no. 2 (1991): 429-438. https://doi.org/10.1137/0151021

[11] King, J. R., and S. M. Cox. "Asymptotic analysis of the steady-state and time-dependent Berman problem." Journal of Engineering Mathematics 39, no. 1 (2001): 87-130.

https://doi.org/10.1007/978-94-010-0698-9 7

[12] Bujurke, N. M., Vishwanath B. Awati, and N. N. Katagi. "Computer extended series solution for flow in a narrow channel of varying gap." Applied Mathematics and Computation 186, no. 1 (2007): 54-69.

https://doi.org/10.1016/i.amc.2006.07.082

[13] Perlmutter, Morris, and Robert Siegel. Heat transfer to an electrically conducting fluid flowing in a channel with a transverse magnetic field. National Aeronautics and Space Administration, 1961.

[14] Attia, Hazem Ali, and N. A. Kotb. "MHD flow between two parallel plates with heat transfer." Acta Mechanica 117, no. 1-4 (1996): 215-220. https://doi.org/10.1007/BF01181049

[15] Attia, Hazem Ali. "Transient MHD flow and heat transfer between two parallel plates with temperature dependent viscosity." Mechanics Research Communications 26, no. 1 (1999): 115-121. https://doi.org/10.1016/S0093-6413(98)00108-6

[16] Adnan, Nurul Shahirah Mohd, Norihan Md Arifin, Norfifah Bachok, and Fadzilah Md Ali. "Stability Analysis of MHD Flow and Heat Transfer Passing A Permeable Exponentially Shrinking Sheet with Partial Slip and Thermal Radiation." CFD Letters 11, no. 12 (2019): 34-42.

[17] Wahid, Nur Syahirah, Mohd Ezad Hafidz Hafidzuddin, Norihan Md Arifin, Mustafa Turkyilmazoglu, and Nor Aliza Abd Rahmin. "Magnetohydrodynamic (MHD) Slip Darcy Flow of Viscoelastic Fluid Over A Stretching Sheet and Heat Transfer with Thermal Radiation and Viscous Dissipation." CFD Letters 12 , no. 1 (2020): 1-12.

[18] Beavers, Gordon S., and Daniel D. Joseph. "Boundary conditions at a naturally permeable wall." Journal of Fluid Mechanics 30, no. 1 (1967): 197-207. https://doi.org/10.1017/S0022112067001375

[19] Nield, D. A. "The Beavers-Joseph boundary condition and related matters: a historical and critical note." Transport in Porous Media 78, no. 3 (2009): 537-540. https://doi.org/10.1007/s11242-009-9344-y 
[20] Bhat, Ashwini, N. N. Katagi, and A. S. Rai. "Analysis of Laminar Flow through a Porous Channel with Velocity Slip." Malaysian Journal of Mathematical Sciences 11, no. 3 (2017): 423-439.

[21] Bhat, Ashwini, Nagaraj N. Katagi, and N. M. Bujurke. "Analysis of Laminar Flow in a Porous Pipe with Slip Velocity." Journal of Mechanical Engineering Research and Developments 40, no. 4 (2017): 526-536.

[22] Keller, Herbert B. "Some computational problems in boundary-layer flows." In Proceedings of the Fourth International Conference on Numerical Methods in Fluid Dynamics, pp. 1-21. Springer, Berlin, Heidelberg, 1975. https://doi.org/10.1007/BFb0019723

[23] Keller, Herbert B. "Numerical methods in boundary-layer theory." Annual Review of Fluid Mechanics 10, no. 1 (1978): 417-433.

https://doi.org/10.1146/annurev.fl.10.010178.002221

[24] Vajravelu, Kuppalapalle, and Kerehalli V. Prasad. "Keller-Box Method and Its Application." In Keller-Box Method and Its Application. De Gruyter vol. 8, 2014. https://doi.org/10.1515/9783110271782

[25] Goldstein, Sydney. Modern Developments in Fluid Dynamics. Oxford University Press, New York (1938). 